\title{
Impact of the Pandemic on Sexual and Reproductive Health Services in Low Income Countries with Reference to Nepal
}

Poudel Thuma Kumari

\begin{abstract}
Access to reproductive health services saves women for safe sex, safe pregnancy and child birth. This paper intends to analyze the impact of pandemic on reproductive health services during one decade 1920-2020 B.S. To achieve the above mentioned objective, descriptive method is used. Data are collected from secondary sources and major biggest pandemic of one hundred years which have larger impact on public health including reproductive health and large scale of mortality. The history of pandemic shows that service delivery of reproductive health to women was seriously affected during pandemic period. There was difficult to achieve basic health facility to pregnant women during pandemic period, they also face problems to achieve reproductive health services. The influenza affects to the pregnant women. They were severely ill during their pregnancy. There was a negative impression with health providers and pregnant women at health centre at the time of providing sexual and reproductive health services during the Ebola virus. The Zika virus effects on women's sexual and reproductive rights. The reproductive health services became at more serious cases at the time of HIV/AIDS pandemic. Pregnant women, infants and young children had serious impact of H1N1 virus. Women are facing problems to get reproductive health services like access of family planning, abortion care and other infectious diseases during Covid-19 periods. These problems also increased risk to unwanted pregnancy, risk of unsafe abortion and risk of STDs to the women. Women were facing lacking of sexual and reproductive health services due to the lockdown, physical distance, travel restrictions and economic slowdown during covid-19 pandemic.
\end{abstract}

Key words: Pandemic, Reproductive Health, Disease and History.

\section{Introduction}

A pandemic is an infectious disease that spreads across a large region. Epidemic is a disease spread rapidly to a large number of people in a given population within a short period of time. A widespread endemic disease with a stable number of infected people is not a pandemic. Widespread endemic diseases with a stable number of infected people such as recurrences of seasonal influenza are generally excluded as they occur simultaneously in large regions of the globe rather than being spread worldwide. Throughout human history, there have been a number of pandemics of diseases such as smallpox and tuberculosis. The most fatal pandemic recorded in history was the Black Death. The term has not been used 
yet but was applied for later pandemics including the 1918 influenza pandemic. The current

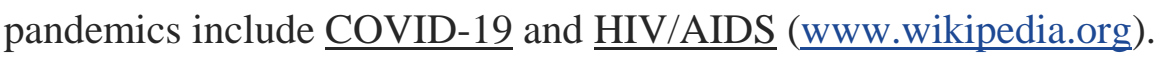

The spread of pandemic (corona virus) has resulted business and schools are closed, hospital services are reduced and redirected to provide only emergency care. At such crisis time women and girls of reproductive age are more suffer from lacking of unmet need of family planning, abortion services and other reproductive health issues. On the other hands, there is a risk of unplanned and risk pregnancies in pandemic period when people became unemployed due to lockdown. In low income country like Nepal unmet for need for family planning is 24 percent (delay child bearing 8 percent and stop child bearing 16 percent) (NDHS, 2016) indicates that there is high risk of unwanted pregnancy and risk of unsafe abortion.

The World Health Organization (WHO) defines health as a state of complete physical, mental and social well-being, and not merely the absence of disease or infirmity. This definition seems idealistic which is relevant and applicable in the area of reproductive health. Reproductive health (RH) implies the absence of disease or infirmity, or the ability to reproduce, to regulate their fertility to practice and enjoy sexual relationships. It further indicates that reproduction is carried to a successful outcome through infant and child survival, growth and healthy development. Finally, it shows implies that women can achieve safe through pregnancy and childbirth without health hazards and safe sex (Fathalla, 1988).

$\mathrm{RH}$ is an integrated package, women cannot be healthy if they have one element and miss another. Moreover, the various elements of reproductive health are strongly inter-related. Improvements of one element can result in potential improvements in other elements. Similarly, lack of improvement in one element can hinder progress in other elements.

Access to reproductive health services is very important for women life. The nine components of reproductive health can save women's life. These cares protect women from pregnancy complications, delivery of mother and new born child. According to WHO reproductive health guidelines, the eight ANC visits (with the first contact scheduled to take place in the first trimester, two contacts scheduled in the second trimester and five contacts scheduled in the third trimester) and one PNC visit (two days after delivery for mother and child) is very important for women's health (WHO, 2016).

Sexual and reproductive health services will be affected by due to the local or national lockdowns compel to shutdown of health services. The physical distancing, travel restrictions and economic slowdowns will interrupt to get reproductive health services during pandemic periods. The COVID-19 pandemic is already having adverse effects on the supply chain for contraceptive devices by disrupting the manufacture of contraceptive tools methods and by delaying transportation of contraceptive commodities. Sexual and 
reproductive health services will be diverted to fulfill the needs, due to the closed clinics and people's reluctant to get health facilities for sexual and reproductive services. It will have impact on abortion care because people will not get potentially lifesaving services (Riley et al., 2020).

In Nepal and India, the government has forced to close clinics to service provider of family planning services without concerted action which hamper to access to essential sexual and reproductive health services (Church, Gassner \& Elliott, 2020). Thus, this study tries to access and analyze the impact of epidemic on reproductive health care practices during one decade (1920-2020).

Reports from frontline service delivery organizations have indicated that the supply of contraception, abortion care services and sexual health services were heavily affected by COVID-19. In several countries, clinics were forced to close due to the strict lockdowns and most of the clinics were operated on reduced hours. Global supply chains for Sexual and Reproductive Health commodities have been severely disrupted due to manufacturing shut downs and import delays. Support and frontline staff have been unable to work due to movement restrictions, illness, family demands or inability to work remotely (Church, Gassner \& Elliott, 2020).

The impact of reproductive health services reduction could increase additional 1.3 million unintended pregnancies in the 37 countries its increased scale of unintended pregnancies could mean an additional 1.2 million unsafe abortions and 5000 pregnancy related deaths (Riley et al., 2020). Thus, the impact of COVID-19 has wider impact on reproductive health services.

Economic challenges due to COVID-19 pose a serious threat to girls and women. The loss of employment / work and business activity expose them to increased risk of exploitation and abuse. On the other hands, evidence from past epidemics shows that diverse of resources from routine health services may limit to the access of sexual and reproductive health services particularly to the girls, women and child health services.

Previous public health emergencies have shown that the impact of an epidemic on sexual and reproductive health often goes unrecognized: its effects are not the direct result of the infection, but the indirect consequences of strained health care systems, disruptions in care and redirected resources (WHO, 2020). We must ensure to address the reproductive health services for women and girls of reproductive age. We must ensure access to continued access to safe delivery, contraception and abortion services. The current use of any methods of family planning is of 53 percent, about 57 percent women are delivered in a health institution in Nepal (MoHP, 2017). 
A study based on nine hospitals found that birthing facilities fell by more than half during Nepal's four-month lockdown. The rate of neonatal deaths more than tripled, from 13 to 40 per 1,000 live births and still births and pre-term births also increased. (https://www.hrw.org/news/2020/08/18/nepal-health-facility-births-decline).

\section{Objective of this study}

To analyze the history of major pandemic during the year 1920-2020 B.S. and its impact on reproductive health of women in low income country with special reference to Nepal.

\section{Data and Methods}

This paper aims to analyze the causes and consequences of major epidemic during one hundred year from 1920 to 2020 B. S. In this way, this article studies the history, nature and impact of pandemic on reproductive health from Spanish Flu (1920) to COVID-19 (2020) B. S. This paper studies the major biggest pandemic and its impact on public health including reproductive health and large scale of mortality rate. The major pandemic studies were: Spanish flu’ (1918-1920), Russian typhus (1918-1922), Asian flu' (1957-1958), Hong Kong flu (1968-1970), HIV/AIDS (1981 to present), Swine flu (2009-2010), Ebola virus (2013-2016), Flu season (2017-2018) and COVID-19 (2019 to present).

Regarding to achieve above objective, analytical and descriptive methods are applied in this paper. The data used in this study is quantitative in nature and were collected from secondary sources like World Health Organization (WHO), United Nations Population Funds (UNFPA), published articles and other organization/ individual research documents.

\section{Results and Discussion}

The Pandemic and Reproductive Health Services Problems

a. Spanish Flu Pandemic, 1918-1920

The Spanish flu was the first global pandemic in the first decade of $20^{\text {th }}$ century. It was caused by the H1N1 strain of the influenza virus. The deadly H1N1 strain of influenza virus had spread to every corner of the world. The mortality rate of Spanish flu ranged between 10 to 20 percent. About a quarter of the global populations were contracting with that flu. The death toll was immense nearly 100 million (Flecknoe, Charles \& Simmons, 2018). Although Spanish flu pandemic mostly affected to young and previously healthy individuals but its impact was also seen on reproductive health matter. Nearly one-half of the pregnant were became patients of pneumonia and one-half of them were died (Harris, 1919).

b. Russian typhus, 1918-1922

After the First World War, a large size of refugee was entered into the Russia. They were suffered from hunger and cholera in the summers of 1918. They suffered from typhus in 
winter of 1919-1920, and in the winter and spring of 1921-1922. The death from typhus, cholera and starvation account around 2.5 million during the 1918-1922 period. The mortality of Russian typhus was around $40 \%$ of an annual birth cohort (Wheat croft, 1983).

c. Asian Flu, 1957-1958

A new influenza H2N2 was first reported in Singapore in 1957. It was spread into Hong Kong in April 1957 and United States in summer 1957. This new influenza A (H2N2) virus also called "Asian Flu". Mainly H2N2 virus was comprised of three different genes from an $\mathrm{H} 2 \mathrm{~N} 2$ virus that originated from an avian influenza a virus, including the $\mathrm{H} 2$ hem agglutinin and the N2 neuraminidase genes. The estimated number of deaths was 1.1 million worldwide and 116,000 in the United States (Huremovic, 2019).

Issue of reproductive health was identified as a risk factor during the 1957 H2N2 influenza pandemic. Nearly $20 \%$ of deaths were occurred during pregnancy were due to influenza and one-half of the pregnant women of reproductive age died from pandemic influenza (Freeman \& Barno, 1959).

d. Smallpox, 1972

Smallpox was a highly contagious disease which was caused by the variola virus. This highly contagious disease was with prominent skin eruptions (pustules) and the mortality was about 30\%. It might have been responsible for hundreds of millions of fatalities in the twentieth century. The smallpox out-broke in the former Yugoslavia in 1972; it illustrated the challenges associated with a rapidly spreading, highly contagious illness in a modern world. It started with a pilgrim returning from the Middle East, who developed fever and skin eruptions. Since a case of smallpox had not been seen in the region for over 30 years, the physicians failed to diagnose correctly the illness. The healthcare providers ended among 38 cases infected by the index case and first fatality (Ilic \& Ilic, 2017).

Although there was no association between spontaneous abortion and smallpox but first trimester smallpox vaccination was associated with a small increase in congenital defects. These were viewed in the context of the high morbidity and mortality of smallpox disease in pregnancy (Badell et al., 2016).

e. HIV/AIDS, 1980

HIV/AIDS is a slowly progressing global pandemic. It was started in the early 1980s in the USA, causing significant public concern as HIV at the time inevitably progressed to AIDS and ultimately, to death. The initial expansion of HIV was marked by its spread predominantly among the gay population with high mortality, leading to marked social isolation and stigma. HIV affects about 40 million people globally and has killed almost the same number of people since 1981. The HIV epidemic is particularly alarming in some Sub-Saharan African countries (Botswana, Lesotho, and Swaziland), where the prevalence was leveled tops 25 percent. In the USA, about 1.2 million people live with HIV and about 
12,000 die every year. Nearly 32 million people were died worldwide during forty years (HIV/AIDS factsheet, 2018).

Women living with HIV/AIDS have a greater risk of certain adverse pregnancy outcomes, such as intrauterine growth restriction and preterm delivery. Pregnant women living with HIV/AIDS have an increased risk of developing malaria and its consequences. Therefore they required additional precautions. Skilled care during pregnancy, childbirth and postpartum includes considering the effects of HIV/AIDS on complications during these events.

Table 1: List of Pandemic and Level of Mortality

\begin{tabular}{|c|c|c|c|c|}
\hline List of the Pandemic & Date & Location & Disease & $\begin{array}{l}\text { Total Death } \\
\text { (Estimated) }\end{array}$ \\
\hline $\begin{array}{l}\text { Influenza pandemic } \\
\text { Spanish flu’ }\end{array}$ & 1918-1920 & Worldwide & $\begin{array}{l}\text { Influenza A Virus } \\
\text { H1N1 }\end{array}$ & 17-100 million \\
\hline Russia typhus epidemic & 1918-1922 & Russia & Typhus & 2.5 million \\
\hline $\begin{array}{l}\text { Influenza pandemic } \\
\text { (Asian Flu') }\end{array}$ & 1957-1958 & Worldwide & $\begin{array}{l}\text { Influenza A Virus } \\
\text { H2N2 }\end{array}$ & 1-4 million \\
\hline Hong Kong Flu & $1968-1970$ & Worldwide & $\begin{array}{l}\text { Influenza A Virus } \\
\text { H3N2 }\end{array}$ & 1-4 million \\
\hline Smallpox & 1972 & $\begin{array}{l}\text { Middle East } \\
\text { Yugoslavia }\end{array}$ & Variola virus & 100 million \\
\hline HIV/AIDS Pandemic & 1981 to present & Worldwide & HIV/AIDS & 32 million \\
\hline $\begin{array}{l}\text { Severe Acute Respiratory } \\
\text { Syndrome (SARS) }\end{array}$ & $2002-2004$ & China, Canada & SARS-CoV & 10,000 \\
\hline Swine flu pandemic & $2009-2010$ & Worldwide & $\begin{array}{lll}\text { Influenza } & \text { A virus } \\
\text { N1H1 } & & \\
\end{array}$ & $2,84,000$ \\
\hline Ebola virus epidemic & 2013-2016 & $\begin{array}{l}\text { Guinea, Liberia, } \\
\text { Sierra Leone }\end{array}$ & Ebola virus & 11,323 \\
\hline Zica Virus & $2015-2016$ & $\begin{array}{l}\text { Brazil, USA and } \\
\text { Caribbean } \\
\text { countries }\end{array}$ & Zica virus & 2400 \\
\hline COVID-19 pandemic & 2019 to present & Worldwide & SARS-CoV-2 virus & $\begin{array}{l}6,58,244 \\
\text { (as of } 28 \text { July } \\
2020 \text { ) }\end{array}$ \\
\hline
\end{tabular}

(Source: https://en.wikipedia.org/wiki/List_of_epidemics)

f. Severe Acute Respiratory Syndrome (SARS), 2002 - 2004 
SARS was the first outbreak in the twenty first century. It was caused by the SARS Corona virus (SARS-CoV). It started in China and affected fewer than 10,000 individuals. It was spread mainly in China, Hong Kong, and Canada. The severity of respiratory symptoms and mortality rate of about 10\% caused a global public health concern (WHO, 2004).

g. Impact of Influenza A (H1N1) in Reproductive Health

Influenza in pregnancy is associated with an increased risk of adverse pregnancy outcomes such as: spontaneous abortion, preterm birth, and fetal distress. WHO has identified the groups that are at increased risk for complications and severe disease from pandemic influenza A (H1N1) 2009 virus infection as including pregnant women and infants and young children less than two years of age. A study of Centers for Disease Control in United States showed that women were severely ill during their pregnancy by H1N1 in 2009. It also affected to child birth. Among born infants who delivered at hospital, 63.6\% were born premature, 69.4\% were admitted to a neonatal intensive care unit (CDCP, 2009).

h. Ebola Virus, 2014-2016

Ebola virus was outbreak in a remote village in Guinea in December 2013 and was spread into the Central and West Africa, Sierra Leone and Liberia. A very small number of cases were registered in Nigeria, Mali and USA. About 11,323 people were killed from this virus. This led to a significant public health and military effort to address the outbreak and help contain it on site (Zoroya, 2016).

According to an analysis of data from Sierra Leone's Health Management Information System, decreases in maternal and newborn care due to disrupted services and fear of seeking treatment during the outbreak contributed to an estimated 3,600 maternal deaths, neonatal deaths and stillbirths - a quantity that approaches the number of deaths directly caused by the Ebola virus in the country (Sochas, Channon and Nam, 2017).

An Ebola outbreak sharply declines in contraceptive use and family planning visits in Guinea, Liberia and Sierra Leone. Contraceptive use and family planning visits had returned to or exceeded pre-epidemic levels six months to two years after the epidemic. The number of antenatal care and delivery had not recovered to prior levels after six months (Camara et al., 2017). Unsafe abortions, unmet need for modern contraceptives, unintended pregnancies were increased. There was 10 percent decline in pregnancy and newborn health care services due to Ebola virus (Riley et al. 2020).

The impact of Ebola virus on reproductive health services distribution had indirect negative effects. The barriers to take reproductive health services during Ebola virus infection are as follows: mistrust of health worker, fear of being refused care or lack of government 
providers, lack of choice to take health service, difficulties in referral of emergencies cases, drugs shortage and expenses for medications and shortage of family planning. In rural area, adolescent reported that government had requested hospitals to stop administrating family planning due to Ebola outbreak. Some women identified that government facility which was no longer offered family planning. There was no way to continue contraception since the Ebola outbreak. Private pharmacies and clinics were closed since the Ebola outbreak, leaving only government facilities available for family planning (UNFPA, 2015).

i. Zika Virus, 2015-2016

Zika virus is a mosquito borne disease but it can also be transmitted by sex. It was first time found in rhesus monkeys in Uganda in 2007 and was identified with human body in Brazil in 2015. The major syndrome of Zika virus are mild illness, causing a flat pinkish rash, bloodshot eyes, fever, joint pain and headaches. In Brazil, in 2015, there were 2400 birth defects and 29 infant deaths due to suspected Zika infection. Since 2016, Zika has continued to spread throughout South America, Central America, the Caribbean, and several states within the USA. It remains a significant public health concern, as there is no vaccine. The reliable way is to avoid the risk for the offspring areas where Zika was identified (Kindhause et.al. 2016).

Although Zika virus infection is a cause of microcephaly but it hampered to fetal brain defects. It threat to the rights of women to become pregnant. The epidemic's effects on women's sexual and reproductive rights, mainly related to inequalities in sexual and reproductive health such as the increased risk of sexually transmitted infections experienced by the poorest and most vulnerable women.

j. COVID-19, 2019

Corona viruses are a family of viruses that can cause illnesses such as the common cold, severe acute respiratory syndrome (SARS) and Middle East respiratory syndrome (MERS). In 2019, a new corona virus was identified as the cause of a disease out broke from China. The virus is now known as the severe acute respiratory syndrome corona virus 2 (SARSCoV-2). In March 2020, the World Health Organization (WHO) declared the COVID19 outbreak as a pandemic.

COVID-19 patients have been classified as asymptomatic, mild, severe, and critical types. Mild patients tend to experience mild pneumonia, while severe patients exhibit dyspnea and increased respiratory frequency within 24-48 hours. Critical patients suffer from respiratory failure, acute heart injury, septic shock, and multiple organ failure (Mungroo et al., 2020; Fraietta et al., 2020) 
People who are older have a high risk of serious illness from COVID-19, and the risk increases with age. People who have existing chronic medical conditions also may have a higher risk of serious illness. Serious medical conditions that increase the risk of serious illness from COVID-19 include: emergency signs and symptoms, trouble breathing, persistent chest pain or pressure, inability to stay awake, new confusion and blue lips or face (www.mayoclinic.org ).

\section{Impact of COVID-19 in Reproductive Health}

Accessing sexual and reproductive health services within community has now become harder almost everywhere. The International Planned Parenthood Foundation (IPPF) released a global survey April 9 shows that over 5,600 community sexual health clinics in 64 countries have already closed due to the pandemic. Most of those clinics have reduced services for HIV testing, contraception, gender based violence and abortion care. Lockdown restrictions mean that clinics are having a harder time transporting and importing commodities and supplies, and are suffering shortages of HIV and contraception medications. Lack of personal protective equipment for sexual health workers also means they can't do their jobs safely. Abortion access has been restricted in other European countries, as hospitals and clinics have reduced or close reproductive health services because of staff shortages (www.bbc.com).

The long-term effects of lack of information include unwanted pregnancies, unsafe abortions and sexually transmitted diseases. Young adolescents, aged 10 to 14 have a higher risk of health complications and death from pregnancy than adults. The WHO reports that complications from pregnancy and childbirth are becoming the leading cause of death for girls and young women aged 15 to 19 years (www.filtermag.org).

According to United Nations Population Fund (UNFPA), the corona virus epidemic could reduce women's access to contraceptive and increase the risk of unwanted pregnancies. There will 47 million women of low income countries may not have access on modern contraceptives. Due to Covid-19, there was 7 million women would face unintended pregnancy during six month period and about 1.2 million. There will be 50 percent reduction in family planning services. Lack of nurse, midwives and emergency services unintended pregnancies will lead to higher maternal mortality rates (www.bbc.com).

Risk to increased unwanted pregnancy: Due to corona virus lockdown Nepali women have also affected from lack of temporary contraceptives. The UNFPA also said corona virus related conditions increased the unintended pregnancies. According to the 2016 Demographic Survey of Nepal, 24 percent of women do not want to have a baby or design 
to have a baby they are capable to use temporary means. Therefore, about twenty four percent of women at reproductive age are at risk of unwanted pregnancy due to lockdown.

Risk of unsafe abortion: Experts say that a lack of access to contraception will automatically lead to unintended pregnancies and risk of unsafe abortions. After the sudden lockdown, people faced the problems of transportations to go to health centre to get services. Due to lack of institutional abortion care service, there will be increased the numbers of unsafe abortions. Marie Stopes International (MIS) predicts that about 9.5 million vulnerable women and girls losing access to contraception and safe abortion services in 2020 which results 2.7 millions unsafe abortion and 11,000 pregnancy related deaths (Kanem, 2020).

Risk of HIV/AIDS: Disruption in global supply chain for contraception could result in more sexually transmitted infections including HIV.

\section{Corona virus affects the male's RH}

Until now, it is unknown whether or to what extent SARS-CoV-2 can affect male reproductive health. COVID-19 is primarily contracted through droplets. However, the virus has already been isolated in the urine, feces and conjunctiva of infected patients. Due to its mechanism of action it may compromise other tissues with ACE2 receptors, such as those of the reproductive system. Specifically, high ACE2 expression levels are found in testicular cells, mainly in somniferous duct cells, sperm at ogonia, and Leydig and Sertoli cells (Fraietta et al., 2020)

\section{Conclusion}

The pandemics are more harmful than seasonal influenza. There was a history of pandemic spread in large region of the world. Health status of people determines the complete physical, mental, social wellbeing not only absence of diseases. It also indicates to the better achievements of sexual and reproductive health and rights. WHO (2016) reproductive health guideline recommends eight ANC and two PNC visits to keep better health of mother and children.

History of pandemic indicates that reproductive health affects seriously time to time. During pandemic influenza 1918, 1957 and 2009, pregnant women were seriously affected from pneumonia. Previous studies showed that the impact of an epidemic on sexual and reproductive health indirect result. The indirect consequences are strained health care systems, disruptions in care and redirected resources.

The pandemic influenza A (H1N1) 2009 virus affect to pregnant women and infants. Women were severely ill during their pregnancy. Among childbirth, who delivered at 
hospital, $63.6 \%$ were born premature, $69.4 \%$ were admitted to a neonatal intensive care unit during influenza A.

The evidence from the Ebola virus outbreak in 2013-2016 in Western Africa shows the negative, indirect effects on sexual and reproductive health services. Results of some studies indicate that contraceptive use and family planning visits had returned to or exceeded preepidemic levels six months to two years after the epidemic. However, in Guinea, the number of antenatal care visits and facility deliveries had not recovered to prior levels after six months.

The Zika virus defected 2400 birth and 29 infant deaths in Brazil in 2015. It remains a significant public health concern. The Zika epidemic effects on women's sexual and reproductive rights. Reduction of reproductive health services may increase unintended pregnancies, risk of unsafe abortion, risks of HIV/AIDS and maternal death. Pregnant women, infants and young children less than two years of age had serious impact of H1N1 virus.

Due to the pandemic of Covid-19, women's sexual and reproductive health services is hampering by lockdown, physical distance, travel restrictions and economic slow down. Women are facing reproductive health service (e.g. access of family planning, abortion care and HIV/AIDS and other infectious diseases) related problems during this pandemic period. These problems also increased risk to unwanted pregnancy, risk of unsafe abortion and risk of HIV/AIDS. Other problems are: mistrust of health worker (demand of PCR report before care was provided), fear of being refused care, lack of choices of health centre, drugs shortage and shortage of family planning devices. These problems may arise due to lockdown, travel restriction and low production, lacking of institutional arrangement of the nations.

\section{References}

Badell M. L. and et al. (2016). Risk association with Smallpox vaccination in pregnancy: A systematic review and meta analysis. PMC, US National Library of Medicine, National Institute of Health 2015 June doi.org/10.1097\%2FAOG.0000000000000857

Camara B. S. and et al., (2017). Effect of the 2014/2015 Ebola outbreak on reproductive health services in a rural district of Guinea: an ecological study. Transactions of the Royal Society of Tropical Medicine and Hygiene. Doi.org/10.1093/trstmh/trx009

Centers for Disease Control and Prevention (CDCP), (2009). Maternal and infant outcomes among severely ill pregnant and postpartum women with 2009 pandemic influenza A (H1N1)United States. MMWR Morb Mortal Wkly Rep 2011 
Church K., Gassner J. \& Elliott M., (2020). Reproductive health under COVID-19-challenes of responding in global crisis. Sexual and Reproductive Health Matters doi.org/10.1080/26410397.2020.177316

Fathalla M. F. (1988). Research needs in human reproduction. Research in Human Reproduction: Biennial Report (1986-1987). World Health Organization, Geneva.

Flecknoe D., Charles W. B., Simmons A. (2018). Plagues \& wars: the 'Spanish flu' pandemic as a lesson from history. Med Confl Surviv. 2018 https://doi.org/10.1080/13623699.2018.1472892

Fraietta, R., Pasqualotto, F. F., Roque, M., \& Taitson, P. F. (2020). SARS-COV-2 and Male Reproductive Health. JBRA assisted reproduction, 24(3), 347-350. doi.org/10.5935/15180557.20200047

Freeman D. W. \& Barno A. (1959). Deaths from Asian influenza associated with pregnancy. Am J Obstet Gynecol 1959.

Huremovic D., (2019). Brief History of Pandemic. North Shore University Hospital, Manhasset, NY, USA. doi.org/10.1007/978-3-030-15346-5_2

Harris J. W., (1919). Influenza occurring in pregnant women. JAMA 1919;72:978-80

Ilic M, \& Ilic I. (2017). The last major outbreak of smallpox (Yugoslavia, 1972): the importance of historical reminders. Travel Med Infect

Kindhauser M. K, Allen T., Frank V., Santhanaa R. S. \& Dye C. (2016). Zika: the origin and spread of a mosquito-borne virus. Bull World Health Organ. 2016.

Kanem, N., (2020). Covid - 19 has devasting effect on women and girls. Sophie Cousins.

Ministry of Health and Population, New ERA, and Micro International Inc (2017). Nepal

Demographic Health Survey, 2016. Kathmandu: Ministry of Health and Population, New ERA, and Micro International Inc.

Mungroo M. R., Khan N. A. \& Siddiqui R. (2020). Novel coronavirus: current understanding of clinical features, diagnosis, pathogenesis, and treatment options. Pathogens. 2020; 9: E297. doi: 10.3390/pathogens9040297.

Nuzum J. W., Pilot I., Stangl F. H., and Bonar B. E., (1918). Pandemic influenza and pneumonia in a large civilian hospital. JAMA 1918;71:1562-5

Riley, T., Sully, E., Ahmed, Z., \& Biddlecom, A. (2020). Estimates of the potential impact of the covid-19 pandemic on sexual and reproductive health in low- and middle-income countries. International Perspectives on Sexual and Reproductive Health, 46, 73-76.

doi:10.1363/46e9020 
Sochas L., Channon A. A., and Nam S, (2017). Counting indirect crisis-related deaths in the context of a low-resilience health system: the case of maternal and neonatal health during the Ebola epidemic in Sierra Leone. Health Policy and Planning. doi.org/10.1093/heapol/czx108.

Today’s HIV/AIDS epidemic factsheet (2018). Centers for Disease Control and Prevention.

U.S. Government. Accessed Oct 2018

https://www.cdc.gov/nchhstp/newsroom/docs/factsheets/todaysepidemic-508.pdf

United Nations Population Fund (UNFPA). (2015). Rapid Assessment of Ebola Impact on

Reproductive Health Services and Service Seeking Behaviour in Sierra Leone. Freetown: UNFP

World Health Organisation, (2015). Ebola situation report—1st July 2015.

http://apps.who.int/ebola/current-situation/ebola-situation-report-1-july-2015

World Health Organization. (2004). Summary of probable SARS cases with onset of illness from 1 November 2002 to 31 July 2003. who.int/csr/sars/country/table2004_04_21/en

World Health Organization, (2020). COVID-19: operational guidance for maintaining essential health services during an outbreak.

World Health Organization. (2016). WHO Recommendations on antenatal care for a positive pregnancy experience. Geneva: WHO.

Wheat croft S. G. (1983). Famine and epidemic crisis in Russia, 1918-1922: the case of sartov. https://www.persee.fr/doc/adh_

Zoroya G. (2016) Military Ebola mission in Liberia coming to an end.

https://www.militarytimes.com/2015/02/04/mil-itary-ebola-mission-in-liberia

https://en.wikipedia.org/wiki/Pandemic

https://www.hrw.org/news/2020/08/18/nepal-health-facility-births-decline-half

https://www.mayoclinic.org/diseases-conditions/coronavirus/symptoms-causes

https://filtermag.org/children-sexual-health-education-pandemic/.

https://www.bbc.com/nepali/news-52691303. 